\title{
Emergency remote teaching at EWB-UFx during coronavirus pandemic: coping with
} (di)stress

\author{
Ensino remote emergencial no ISF-UFx durante a pandemia por coronavirus: lidando com o stress
}

\author{
Elaine Maria Santos \\ Universidade Federal do Sergipe - UFS - Sergipe - Brasil
}

Rodrigo Belfort Gomes

Universidade Federal do Sergipe - UFS - Sergipe - Brasil

\begin{abstract}
As coronavirus pandemic has spread all over the world, schools and universities needed to reinvent themselves so that their students could be remotely assisted. In this context, this paper aims to present and detail the experiences of English without Borders Program at the Federal University of XXX with Remote Teaching, highlighting the actions related to the planning sessions, as well as the difficulties teachers and coordinators faced and the adjustments that were necessary. The analysis was carried out using the case study methodology, with teachers' feedback collected from pedagogical meetings and questionnaires sent by e-mail. The remote teaching modality was contrasted with e-learning, and among the conclusions presented, it was evidenced that the initial difficulties with the promotion of interactions among students were reduced when the feeling of community identity built during the classes was perceived. The teacher training process developed to assist scholarship holders in this new educational scenario was also endorsed as a differential of the program, with the indication that sharing experiences with remote education is necessary so that educators can be prepared for a future surrounded for uncertainties.
\end{abstract}

Keywords: Remote Teaching. English language. Languages without Borders-English. Coronavirus pandemic.

Resumo: Diante da pandemia do COVD19 que assolou todo o mundo, as escolas e universidades precisaram se reinventar para que seus alunos pudessem ser assistidos de forma remota. Nesse contexto, o objetivo desse artigo é o de apresentar e detalhar as experiências vivenciadas pelo Ensino Remoto de Língua Inglesa do Programa Idiomas sem Fronteiras da Universidade Federal de XXX, destacando as ações relacionadas ao planejamento dos cursos, bem como as dificuldades encontradas e os ajustes que foram necessários para que as aulas pudessem ser colocadas em prática. A análise foi feita utilizando-se a metodologia de estudo de caso, com o feedback dos professores colhidos a partir das reuniões pedagógicas e de questionários enviados por e-mail. A modalidade de ensino remota foi contrastada com o e-learning, e entre as conclusões apresentadas, foi evidenciado que as dificuldades iniciais com a promoção de interações entre os alunos foram diminuídas com a percepção do sentimento de identidade comunitária construído ao longo das aulas. O processo de formação de professores desenvolvido para auxiliar os bolsistas nesse novo cenário educacional foi também referendado como um diferencial do programa, com a indicação de que o compartilhamento das experiências com ensino remoto é necessário para que os profissionais da educação sejam preparados para um futuro cercado por incertezas.

Palavras-chave: Ensino Remoto. Língua Inglesa. Idiomas sem Fronteiras-Inglês. Pandemia por Coronavirus. 


\section{Introduction}

In 2020, we faced a 'to be or not to be' dilemma, and beyond any philosophical reflections upon life and society, we found ourselves forced to reinvent ourselves, take care of families, and begin to fight for survival. Recalling our experiences learning about Maslow's hierarchy of needs in our undergraduate psychology classes, we were finally able to understand the importance of the lower level of the pyramid: the physiological needs. It suddenly became clear to us that air that we breathe, which we so often take for granted, now needed to be our primary focus and concern. Coronavirus, in many ways, took away the most important thing in our lives: safe air. As a consequence, we have been forced to start looking for protection. The isolation measures were (and still are) vital, if we are to avoid high levels of infection and the possibility of the healthcare system being overwhelmed with a high demand for hospital beds and respiratory equipment.

Given this context, many people have stopped working in order to save as many as possible lives. Schools and universities were the first to stop their activities due to the large numbers of people who regularly gather together in enclosed environments. In public universities, it is important to note that while inperson classes were canceled, professors continued to work in different areas, such as research, online meetings, and online activities for students and the external community. Many institutions quickly implemented remote teaching. Bearing in mind the educational scenarios that were implemented due to COVID19, this paper aims to present some considerations on the differences between on-line learning and remote teaching, as well as present a case study on the remote teaching which was implemented at the Language without Borders Program (EWB) at the Federal University of XXX (UFX). In particular, this paper will depict how the program's planning sessions took place, the activities undertaken, the evaluation process, the difficulties faced by students, teachers and coordinators and how each new course was prepared based on the previous experiences.

Including a case study (CROWE at al., 2011) was important for this paper, since it allowed us to conduct an in-depth qualitative and quantitative analysis of the remote teaching practices in the EWBUFx program. By doing so, we were able to take into consideration the viewpoints of the teachers and coordinators who were totally immersed in the process. After describing the classes and the impressions collected from the participants involved, we offer some reflections on the lessons learned and propose an Emergency Remote Teaching (ERT) plan to be used in case such measures become necessary again in the future.

\section{Languages without Borders: a brief retrospective}

Languages Without Borders (LWB) is a national program in Brazil, initially sponsored by the Brazilian Ministry of Education (MEC). The program was promulgated in 2012 as English without Borders (EWB) but its initial scope was eventually broadened, and with the Ordinance number 974 on November 14th, 2014, it became Languages without Borders (LWB). The activities conducted at LWB aim to develop the linguistic proficiency of the academic community (including students, faculty and staff) in Brazilian universities, which contributes to the internationalization processes carried out by the International Affairs departments of all affiliated universities. The program also fosters teacher training programs for undergraduate students who teach for the program.

Besides English, other languages were included in the program in 2014, like Spanish, Italian, French, German, Japanese and Portuguese for foreigners. The Federal University of $\mathrm{XXX}$ offers courses in English, French, Spanish and Portuguese for foreigners. In order to support students interested in academic mobility programs, EWB offers language classes focused on academic issues and vocabulary. As a result, students are able to improve their level of proficiency enough to obtain a proficiency certification 
that is internationally valid and required in anglophile universities around the world.

For this paper, we highlighted the activities developed by the Languages without Borders' English program at UFx, taking into consideration that in April 2020 , even with social distancing measures in place, EWB resumed some of their activities through remote teaching. Before we describe the activities and planning that were necessary for this shift, it is important to explain how EWB worked before the pandemic. From 2013 until 2019, the program covered three main areas: English teaching for undergraduate students, faculty and staff; an on-line course (My English Online - MEO) covering levels from $A 1$ to $C 1$, from the Common European Framework of Reference for Languages (CEFR); and the TOEFL ITF (Test of English as a Foreign Language - Institutional Testing Program) via proctored test-taking sessions.

The TOEFL ITP tests were proctored at the Federal Universities of Brazil as a means to gauge the English proficiency levels of the academic community, and also as an opportunity for students and researchers who needed to certify their level of English proficiency in order to apply to certain anglophile universities.

The initial purpose of EWB was to serve the Science without Borders (SWB), another federal program for academic mobility, which was responsible for sending many Brazilian students to universities around the world, and especially to the US. SWB ended in 2017, but LWB continues due to the program's good results and the increased interest manifested by the students, who continuously sign up for the courses.

In June 2019, the MEC stopped sponsoring the LWB program, and all of the existing scholarships were canceled. From that moment on, coordinators all over Brazil have had to cope with management problems, since they had to look for institutional scholarships, which were, in most cases, three times lower than what they had previously been paid. As a consequence, the Federal University of XXX LWB program was forced to reduce their course offerings. Instead of having teachers with three groups of 25 students each, each teacher was given a single class group per month. This reduction meant that the LWBUFx Program offered only 150 spots per month. Four months later, in November 2019, LWB migrated to the National Association of Managers of Federal Institutions of Higher Education (Andifes), while maintaining an institutional partnership with the MEC. The Program was renamed the National Andifes Network of Experts In Foreign Language - Languages Without Borders (Andifes Network - LWB).

The EWB team at UFx is composed of a general coordinator, a pedagogical one, the students who handle administrative affairs, and the undergraduate students who teach in the program. The EWB courses are not meant to be taken in sequential order. This means that students who take an A2 course are not necessarily going to B1 afterwards. Course length may vary between $16,32,48$ or 64 hours, and the same student may take several courses from the same level until they succeed in proving that they can partake in more challenging groups. They may only join more advanced levels if they are able to present a certificate that attests to their language proficiency. Taking into consideration that the program was designed to help the internationalization processes in Brazilian universities, all courses primarily use academic language, with the goal of preparing students for academic writing and oral presentations. Furthermore, the courses also highlight the cultural aspects of language. As it is a national program, every affiliated federal university must offer the courses listed in the national course catalog, which is collaboratively prepared and lists all the courses offered at all of the federal universities together with information on each course, course objectives, and references for the students. Doing so ensures a cohesive program, with information and data that can be easily disseminated and researched by the coordinators and teachers of the Program.

The changes to the program in 2019 caused distress among many coordinators and teachers, who had to reinvent themselves in face of a new scenario. Without scholarships, they had to find new ways to continue offering classes while also addressing internationalization issues. Just as the program was 
beginning to find its footing again, the COVID-19 situation forced the team out of their newfound comfort zone into preparation mode for socially distant classes during the quarantine.

\section{Reinventing EWB during the Coronavirus pandemic: online learning vs. remote teaching}

Due to the new coronavirus restrictions, professors all over the country started to discuss how universities would adapt to the crisis. The main concerns were related to the consequences of moving to online teaching and the possible exclusion of part of the academic community, those who might not have access to a computer, a mobile device or internet data. According to Arruda (2020), public universities have been cautious about resuming classes due to the nostudent-left-behind policy, and this is why remote teaching has not been implemented at UFx so far,. In July, a committee was created, made up of professors, pro-rectors and students, with the goal of preparing a complete plan to implement remote teaching at the beginning of October. There is as of yet no consensus on this matter within the academic community, which remains reluctant to resume classes without first making sure that all students will be able to attend classes virtually and whether they will face a lack access to electronic devices and internet connections or other issues related to infrastructure and emotional distress.

The prospect of remote teaching also haunts professors who fear that online teaching will ultimately replace in-person classes after this experience. We believe this fear may reflect a misunderstanding of the principles behind remote and online teaching. As Hodges at al (2020) states,

emergency remote teaching (ERT) is a temporary shift of instructional delivery to an alternate delivery mode due to crisis circumstances. It involves the use of fully remote teaching solutions for instruction or education that would otherwise be delivered face-to-face or as blended or hybrid courses and that will return to that format once the crisis or emergency has abated (HODGES AT $A L, 2020, n / p)$.
Once the crisis is over and a vaccine is readily available, there would be no reason to continue working and teaching remotely. This shift towards remote teaching is a temporary adaptation of the courses that would normally be taught in a traditional in-person setting, but which needed to be altered due to the circumstances of the moment. We are not referring to online learning, which has a totally different structure and well-established procedures.

It also needs to be highlighted that the entire concept of online learning greatly differs from ERT, since the former has a specific format and requires strategic planning. As Hodges at al (2020) discuss, when we talk about online or remote learning, we are referring to specific teaching and learning processes in which instructional design and planning are necessary, a platform is used and prepared for the classes and evaluations, and the synchronous and asynchronous interactions are planned in advance, thereby using a systematic model for design and development. This is totally different from the ERT model, in which teachers use technological tools for teaching, without this same type of systematic preparation. To further illustrate the complexity of distance education in terms of the design and decision-making process, Hodges et al (2020, n/p) highlight nine important dimensions which must be considered: "modality, pacing, student-instructor ratio, pedagogy, instructor role online, student role online, online communication synchrony, role of online assessments, and source of feedback". Maia and Mattar (2008) share the same belief, and add that online teaching requires some actions that go beyond concerns with content, such as needing to meet aesthetic standards and being able to work with a large team capable of supporting the faculty involved in the process. As a consequence, Emergency Remote Teaching cannot be defined in the same way as online learning. The context that we are in due to the coronavirus pandemic may lead us to ERT, but it does not mean that we necessarily approve of this replacement. It is not a matter of substituting practices. It is a question that goes beyond our powers, since we cannot stop the coronavirus without a vaccine.

What we can learn from this situation is that it is not a matter of choosing remote 
education or face-to-face one, but the need to discuss an unprecedented context in which information is updated daily and, as we said, it is not possible to make projections about the return of face-to-face classes (ARRUDA, 2020, p. 268).

Even if the widespread use of ERT is implemented, public universities must prepare contingency plans in order to help the students who will be unable to attend online classes due to a lack of access to learning devices and internet connection. It is vital that students' interests be preserved and all measures that help students gain access to the ERT classes be implemented.

The impact of the closure of educational institutions goes far beyond the immediate concerns of students facing difficulties in finishing their studies. A lack of social interaction emerges as one of the potential problems that may jeopardize the healthy development of social skills among kids and teenagers. Infrastructural and psychological problems may also be observed for the teachers and professors, such as difficulties in finding a proper space in which to conduct classes; difficulty focusing when their physiological needs are in danger; and lack of access to the equipment required to participate in the remote teaching environment. Communicating effectively with students during this time and helping them cope with anxiety and the difficulties mentioned above may be beneficial if professors succeed in bringing these kinds of discussions to the universities, as suggested by Arruda (2020).

Little by little, the institutions are trying to resume classes by taking advantage of ERT. UNESCO is trying to help the world by tracking the number of students affected by COVID-19 as well as those who returned to their studies without facing the stress of a face-to-face course. They are tracking the timing and duration of school closures, relating the information about the number of affected students, and displaying this information on an interactive map, which is updated weekly. To have a better idea of the educational scenario, we analyzed the map on three different dates: May 25th, Jun 25th and Jul 25th 2020.
Through this analysis, we discovered that the number of country-wide closures decreased $22 \%$ from May to June, but only $7 \%$ from June to July, as these two last maps are quite similar. It is possible to infer that we are far from "normalcy", and almost $61 \%$ of students enrolled in any level of education have been affected worldwide. It is time to try to narrow the distance between universities and their student populations, so that they may reopen not just spaces in which knowledge is exchanged but also a space in which professors can listen to and interact with their students.

Taking into consideration the fact that the discussions on re-opening have been long and exhausting, the English without Borders program at UFx has tried to get closer to its students, offering some support with language learning and promoting interaction in a moment in which social distancing remains a strict rule. In light of the needs of the moment, it is vital to collect data about students' experiences and share these with the academic community in order to help others face the same problems going forward, given that our future concerning similar pandemics is far from certain.

On April, 15th EWB classes resumed at the Federal University of XXX. After two weeks of meetings and planning sessions, we came up with a new format. We continuously evaluated and modified our updated program based on the feedback that we received from teachers and students, as well as the discussions led by the coordinators in weekly meetings. The English teachers began working in pairs, teaching hour and a half class on a weekly basis. Classes were divided into basic, intermediate and advanced levels, and employed the post-method condition (KUMARAVADIVELU, 1994; 2001), which states that foreign language educators must be able to apply language principles according to students' needs and realities, thereby avoiding methods which are applied universally with no thought as to each group's specific needs. Teachers are then encouraged to practice and expand upon this theory based on their own experiences. Teachers ultimately plan their classes autonomously, experimenting with new techniques and 
methods, provided that the objectives are well set and delineated.

Up until July 30th, EWB-UFx had resumed activities for 16 weeks, with a total of 80 classes, covering different themes, like fake news, quarantine routine, diversity, learning a foreign language, anxiety, gender equality, online traveling, nature, technology, culture and identity. It is important to detail the planning sessions and how the platform (Microsoft Teams) and resources were used, before we analyze teachers' feedback. Certainly, not everything has been successful. We have had to re-plan activities and change strategies after receiving feedback from students and attempting to better understand their needs and suggestions. These experiences and subsequent difficulties have been extensively discussed among the EWB leadership, and new actions and decisions were collaboratively taken to improve the students' (online) classroom experience.

From April to July, weekly meetings were held via Microsoft Teams. Teachers planned lessons in pairs, which were then submitted for analysis by the coordinators and later adjusted by the teachers. We also held fortnightly readings and discussions on theoretical texts. Students' feedback was analyzed regularly, which helped us in the re-planning sessions. In listing these actions, it may appear as though everything went as planned, without any problems or setbacks. In the next section, however, we will describe the need for adjustments during the program's adaptation to this new teaching modality.

\section{Overcoming difficulties and paving the way}

\section{for a new horizon}

For the first time, the EWB team worked totally from a distance. This became our first challenge, since we were used to having weekly face-to-face meetings where we not only addressed administrative and pedagogical affairs, but which also served as moments for socialization and teambuilding. In the meetings, we decided to divide the ten EWB-UFx teachers into pairs, and each pair planned lessons, submitted them for evaluation by the coordinator, made the necessary adjustments, and finally, conducted the classes. Classes were publicized on our social media accounts, and e-mails were sent to former students telling them about the classes in this new format.

From April to July, we faced many different situations, and re-planning was necessary in order to obtain our desired results. In order to understand the shifts in the processes which were carried out by the EWB group, we divided our analysis into four different phases, which will be known as phases $A, B, C$ and $D$.

In phase $A$, at the end of the first month, the main problems that teachers faced were the difficulties with using the educational platform, faulty internet connections, and low numbers of students enrolled in the courses. As the Federal University of XXX had adopted Microsoft Teams as one of the possible virtual learning platforms for the long-term, we spent the first weeks of April trying to get familiar with the tools provided by the platform, as we did not know how to interact with the students in this new educational context. We wanted to have an Emergency Remote Teaching interface that promoted the interaction between students and teachers and offered a space in which the four core language skills-listening, reading, writing and speaking — could be practiced as equally as possible. After each class, teachers took advantage of the EWB-UFx WhatsApp group to discuss new discoveries about the Teams, and without this collaborative learning it would have been much more difficult to overcome this first obstacle.

Many teachers also struggled with low-quality internet connections, which is one of the primary reasons many professors all over Brazil are against the widespread use of ERT in educational institutions. Initially, we imagined that slow internet speed would be a problem that only students would face. Surprisingly, however, it was not just the students, but also the teachers who encountered difficulties in maintaining a stable internet connection for the duration of the class. In order to minimize these problems, each one of the two teachers needed to have a second device with the PowerPoint presentation ready to be shown, so that their co-teacher would be able to take over the class in case the first teacher's connection wasn't good enough 
to show video. Our other main problem during phase $A$ was the number of students who attended the classes. We expected to have about 15 students in each class, but it was common to have just a few students or even no students in some of these initial classes. By analyzing each case, we were able to identify some recurring situations. Using Instagram, we conducted a series of surveys to identify days, times and topics for classes that students would be more interested in, and this information helped us make the necessary adjustments. We then observed that there were less students attending the basic classes than the other class levels. By talking to some of the students and teachers, we concluded that the stressfulness of the quarantine was more intense for the basic students when taking part in the classes. Beginner students not only had to cope with the difficulties of the pandemic, but also the intimidating idea of interacting in a new language via an online platform and the fear of being vulnerable in an environment where they were not comfortable.

By the end of May, at the beginning of phase B, we identified other problems and created new strategies. We realized that we were attempting to apply face-to-face educational practices in an online scenario, which made us rethink the types of activities, interactions, and classes we were offering our students. Even though we were aware of the differences between e-learning and ERT, it was only when the classes began that EWB teachers were truly able to appreciate how different they are. These differences are highlighted by Gags et al. (2020), who reported some of the problems that could arise in ERT scenarios, due to

limited capacity for training, minimal, if any, access to appropriate technological resources for instructors and teaching assistants, no access to campus facilities, increased fully online workload with limited personal learning spaces, and the emotional and financial trauma of this pandemic (GAGS et al.., 2020, p. 381)

Our class materials initially consisted of a PowerPoint presentation that was shared with the students during the classes, as well as downloadable handouts in which students could answer questions during the class. After some weeks of classes, the lack of proper interaction became clear. It was necessary to include more online resources and activities in order to diversify the class and make it more interesting and interactive. We decided to include more sites and apps as part of the classes, and increased the amount of group work. Students responded well to the changes and participated more frequently in the proposed activities.

The teachers also noticed that students' cameras and audios were turned off for most of the class, which made interacting more difficult. In our first attempts we tried to make students more comfortable and respected their timing when it came to oral participation. We then decided to have a slightly more aggressive approach, and started to kindly ask students to turn on the cameras when they were talking. Teachers also called silent students by their names and asked for their opinions. As a result, some students started to participate more, which then gave other students the confidence to do the same. By sharing opinions and showing their faces more frequently, each class gradually formed a group identity. Students began to ask their classmates to participate, and even started to ask them to turn cameras on. The level of familiarity grew, and some groups even developed internal games and jokes, like creating funny backgrounds based on memes that would then be used in class. Asynchronous activities were also assigned in some groups, in order to improve interaction with the teacher. Small written projects were also assigned, which students had to email to the teachers in order to receive corrections and feedback.

In the third month, phase $\mathrm{C}$, the teachers reported low student attendance during classes as being the program's primary weak point. The EWB-UFx leadership addressed this issue by advertising the classes more using social media networks and began to offer a wider variety of class topics. Instead of having classes solely focused on academic issues, we introduced game afternoons, contest series, online movie sessions, and book clubs. Encouraged by the students' positive reactions, we decided we wanted to increase the number of participants even more. In order 
to achieve this, we changed the nature of the program's activities and began using the academic credit system to register students in 16-hour courses, in which students with $75 \%$ attendance received a certificate upon completion of the course. Students seemed to be pleased with this new format, since all 30 spots were occupied in each of the five class groups. These classes were ministered in July, the last month of this study, and we may say it was a success, based on the good feedback from the students and their high levels of participation, as is shown in phase $D$.

Phase D was characterized by our first major piece of feedback, in which we were able to analyze our results and adopt new directions after the two-week break between classes. Since a lack of student participation continued to be a problem in the classes, teachers dove into further researching and analyzing the virtual learning environment. They then discovered a way to have students work in small groups or pairs, by creating separate "rooms" within the virtual classroom. By doing so, students were able to migrate to these rooms and then return to the original space once they had finished their partner or group work. Teachers were able to monitor these groups by visiting these separate spaces and giving feedback. Students reported that by working in small groups, they gained even more familiarity with one another, further motivating even more students to turn on their cameras within their small group settings.

Student interactions continued to improve due to the large number of students who decided to turn their cameras on, as they felt increasingly comfortable and confident with each other. Students wanted to feel as if they were part of a group dynamic, and since they had already spent some time together individually, they started to participate more in the large group setting. Teachers observed that students began talking more freely with one another, even making plans to sign up for the same courses in order to continue together as a group. Harrison and Thomas (2009) discuss how identities in online communities are formed, and state that "individual members will construct their own personal identity through their profiles and the community as a whole will construct a cultural identity through the linguistic codes". Adapting this idea to the reality faced by the EWB teams, we may say that besides the linguistic enhancement provided by the classes, other important aspects were also present, such as the connections which students established based on the exchanges of opinions and jokes in all of the classes. In the pedagogical meetings, it was clear how different each community was from each other in terms of how noisy they were, the level of openness and seriousness, the amount of inside jokes, and the topics that were always brought up during discussions.

The differences between ERT and E-learning were clearly visible in our meetings. We all had the feeling that we could strengthen our bonds with our students, who were in need of educational and emotional help, yet we were not familiar with the available tools and resource. Indeed, many of the most successful adjustments that we discussed in our replanning sessions were due to the fact we were not able to anticipate all of the problems. E-learning is a structured educational system, well-planned and implemented on a solid basis. Emergency Remote Teaching, on the other hand, has been a learning process for all the actors involved in the process, since we did not have enough planning time nor the institutional support for guidance or proper training. But this lack of support was not due to negligence by the university. On contrary, UFx tried to help us with some online courses and providing the Teams platform for our use, but a program-specific strategic plan was vital to our courses' eventual success.

More classes will be open for enrollment, and the same planning and execution process will be used. Teachers will plan classes in pairs, and the coordinators will analyze their proposals. The program leadership will receive and offer feedback in every weekly pedagogical meeting, and changes will continue to happen according to the observations. For the next set of groups, an evaluation process will be implemented, with two main objectives: to get more accurate feedback on the learning process, and to prevent students from earning a certificate if they do not actively attend and participate in the classes. There are people who enroll in the courses, but do not turn on 
their cameras or participate, and they occupy a place that could be better utilized by someone who would be genuinely interested in the course

\section{EWB-UFx experience: lessons learned and open possibilities}

In the previous section, we described the EWB courses at the Federal University of $X X X$, pointing out the difficulties, solutions and improvements during the implementation of an emergency remote teaching (ERT) format. We will now compare the impressions shared by the teachers who dealt with the digital platform logistics, their students and this new teaching modality. The coordinators sent a short questionnaire to be answered by the program's ten teachers, which all of them answered. In this questionnaire, each teacher chose a fictitious name and was asked to describe their experiences teaching English prior the pandemic; the difficulties that they faced during the time they had to teach remotely; how they coped with the students' interactions; the feedback they got in class; and the lessons that they learned.

Only one out of the ten teachers had taught inperson classes before teaching at EWB, which made the program an important part of the teachers' training. Their hands-on experiences and the discussions afterwards helped them compare theory with practice. One of the teachers reported some previous experience with private classes, and another reported having participated in a national teaching program (PIBID), in which language students from the university work in pairs as co-teachers in a public school and were supervised by another teacher from the institution.

The main difficulties that the teachers reported were related to the internet quality and the initial problems in trying to ensure students' participation in the class. One of the teachers, Joanne, expressed her anxiety with the "unpredictability of the internet connection", since she never knew when it would work properly. Another teacher, Isabel, had the same opinion and admitted that she is not very good with technology, which tends to make her feel a bit stressed.
For EWB teacher Heloísa, dealing with the internet connection was definitely her biggest difficulty. Another teacher, Joana, also reported this problem, stating that the only element of the class which her students described as negative was "related to connection issues or platform malfunctions" and not to the content of the class.

When it came to analyzing the student interactions during their classes, all of the teachers mentioned that students' unwillingness to participate was their main difficulty. They were so used to teaching in face-to-face environments that dealing with students who turned their cameras off was initially a bit frustrating. Later on, however, they reported that as the students began to identify more with the class's group dynamic, they started to get more comfortable showing their faces, and their interactions improved

Another difficulty, or rather a challenge,
is that we cannot see students'
reactions (body language, face
expressions etc.). Even when they turn
their cameras on, we can see a small
image of them. In this situation we
cannot really see how they are
responding to the activities. For
instance, in a more basic class, by
looking at students' facial expressions,
we can see if they are understanding
what we are saying and, based on that,
rephrase what we said or use another
strategy to make sure students
understand. To deal with that, formative
assessment becomes even more
important; we must invest on this kind of
assessment and look for ways to see
how students respond to the activities,
exploring multimodality and using the
many resources available online
(JOANNE)

Another problem that the teachers reported and discussed in our pedagogical meetings was related to getting feedback from students. Students' participation and consequent feedback was essential in the planning sessions, given that the classes were prepared based on students' needs. EWB teacher João Lucas believed that the initial difficulties in promoting student interactions were partially due to the lack of familiarization with the online platform. Once the teachers mastered the tools offered by Microsoft Teams, they were able to achieve better, though it did 
take them significant time to achieve this. Another teacher, Julia stated that 'students' interactions through chat and voice at the same time" made her feel confused, due to her "lack of experience with technological resources".

EWB classes may be classified as hands-on teaching experiences. In an e-learning environment, all of the adjustments within the platform and training for personnel are done before the beginning of the course. The entire system is prepared for the course before the students enroll in it. In Emergency Remote Teaching, problems arise as an opportunity for us to find creative solutions. These solutions will not necessarily be permanent, however, as the full scope of the problem is not always immediately clear. This may explain why, according to EWB teacher Ana, the initial problems remained recurrent. The most common of these were the teachers' "difficulty with the [Teams] platform, due to the[ir] lack of experience in its use, and the availability of quality internet on the day and time of the class. These kinds of problems still happen today" (ANA).

Working in pairs lowered teachers' anxiety, since they never knew how the internet quality would be during their classes. Joanne admitted that she felt relieved, knowing that "working in pairs with other teachers is a strategy that helps, given that one teacher is there to continue the class in case the other is unable to do it" (JOANNE). During the weekly meetings, teachers and coordinators noticed that it is also common for teachers to struggle with an unclear video stream or difficulties with opening the microphone. Frozen screens are also recurrent problems, as well as audios that cut out when a person is speaking. Though these kinds of things continue to happen, they do not seem to bother the teachers anymore because they know that their colleagues will be there to continue the class in case of a problem. This is still a new challenge for them: the classes need to be very well planned and discussed, because if one teacher has a bad internet connection, he/she needs to trust that their co-teacher will be prepared to finish the class.

Teachers emphasized that the lack of interaction among students was one of the biggest challenges in conducting ERT classes. When referencing the techniques that they used to improve this issue, all of the teachers pointed to students' increasing bonds with one another over time as the main reason for an increase in their interactions during class. It was a consensus that at first, "most of the students do not feel comfortable to interact but, as the classes go [on], they create bonds that make the environment less threatening. Pair and group activities are great to help students get to know each other better and with that comes the confidence" (PEDRO). EWB teacher Rose mentioned that she felt the teachers were "talking to the void" during the earlier classes, in which students avoided interacting with one another altogether. However, after the first few students started getting more comfortable with one another, the situation changed. Little by little, students started to turn their cameras on. Because of this, "interactions got a lot better and more fluid" (ROSE).

After the adaptation period, all teachers noticed a better response from the students, especially those who were not familiar with the new online class format in the English without Borders Program. Initially, we did not have many students in each class group, possibly because they were afraid of appearing in front of the camera. The idea of registering the courses in the university system, with the possibility of receiving a certificate, was responsible for increasing the number of enrolled students in the classes. Prior to offering certificates, the first few class groups often had three or four participants, but with the new format, all of the available class spots were filled. EWB teacher Pamela identified the course certificates as being an important factor and thereby necessary to analyze, since with a bigger group came new challenges. For example, teachers needed to find strategies to allow more time for students to be able to take turns speaking and participating during the classes. According to her,

As for the engagement of the community, at first, it was very low even though many strategies were employed to attract more students. However, with the release of the certificate courses, students started engaging more. As for the students' behavior in the classes, I believe students' excitement towards the subjects addressed and the discussions proposed continues; 
however, due to this new format, they have to organize more the speech turns (PAMELA).

By July, both students and teachers seemed satisfied with this new emergency remote teaching format. They expressed gratitude for being able to continue their studies during the pandemic, as well as for the time they were able spend together. Indeed, it was common to have some students taking part in all five of the courses offered each month, demonstrating that the new format of classes was meeting their needs. As it has been stated before, a feeling of belonging among students can clearly be observed, as they appear to have developed a strong community identity. It is interesting to note that the teachers themselves participated in the creation of these community dynamics. One EWB teacher, João Lucas, included himself in the bonds that were strengthened during his class.

We can notice that they [students] are trying their best and willing to make the most out of these opportunities. Throughout the four months of remote classes we had some students that came to almost every class, so we can see that there is a bond arising between us, even though the national environment is a little troublesome for several individuals (JOÃO LUCAS).

Even knowing that this is a temporary situation, in which classes were remodeled to suit students' needs, the teachers recognized it as an important moment to improve their teaching skills, especially because the future is uncertain and it is important to be prepared for similar scenarios. EWB teacher Isabel summarized this feeling by stating that she knows she can apply what she learned in ERT "to any class, even in regular conditions, because students seem to get genuinely interested in learning when we use multiple resources in our classes". Joana was also aware of the new possibilities that ERT brought when she mentioned that

Online classes take away a lot of resources, but also give us new ones. The main lesson learned is that we can always do a good job as long as we are willing to learn and adapt to new teaching scenarios. After the first moments of adaptation, I see that I can develop my classes better and better (JOANA).
The teachers of the EWB-UFx program affirmed that in this new way of teaching, the use of different resources is vital, and they must continually seek out new applications and materials that may be useful. Everybody wants to go back to their "normal" lives, but the truth is that we do not know what this "normality" will look like in the coming months or years. With this in mind, it is important to take advantage of every opportunity to learn how to deal with these particular challenges and situations, in order to minimize the damage within our educational context and communities.

\section{Conclusions}

The global outbreak of COVID-19 was responsible for many changes in our routines, not just concerning safety measures and hygienic protocols, but for everybody who has needed to adapt to being in indefinite confinement. In terms of the educational field, many adjustments have been necessary. Nobody ever imagined that schools and universities all over the world would be closed for so long, and despite the risk for some students of being unable to participate in online learning, ERT had to be implemented or at least taken into consideration, in attempts to avoid even worse damages.

The long-term effects of this pandemic are still uncertain, and systematic study must be carried out, especially since successful remote classes can take longer to prepare and achieve than what might have been imagined so far. The academic community (students, faculty and staff) must adapt to this new teaching mode as swiftly as possible, and this is why the English without Borders Program from the Federal University of XXX has been implementing ERT since April 2020.

All of the difficulties that the EWB-UFx currently faces and that were presented in this paper show us how important it is to learn to adapt to unfamiliar situations and to be open to using new tools and strategies. Thus, without a shadow of a doubt, we conclude that while we do still have a lot to learn, our experiences may be able to help other professors and researchers who are facing the same problems and are in need of proven solutions. This subject needs our attention urgently, considering that a remote teaching format is neither a replacement for face-to-face classes nor an application of E-learning solutions. 
We also consider it important to analyze EWB classes through the teachers' eyes, listening to their voices and collecting their testimonials, which may contribute to the research in this field, as well as act as a resource for other teachers who face similar situations and identify with the problems and solutions presented here. As it was highlighted, most of the teachers in the EWBUFx program who worked with ERT, considered this teacher training to be a unique growth opportunity and valued this experience as something that impacted their lives positively. Further studies on the topic are also important and will be carried out, focusing even more on the students' perspective.

\section{REFERENCES}

ARRUDA, E. P. EDUCAÇÃO REMOTA EMERGENCIAL: elementos para políticas públicas na educação brasileira em tempos de Covid-19. EmRede, v. 7, n. 1, p. 257-275, 2020. BROOKS, C.; GRAJEK, S. (2020 March 12). Faculty readiness to begin fully remote teaching. Educause Review. https://er.educause.edu/blogs/2020/3/faculty-readinessto-begin-fully-remote-teaching

CROWE, S.; CRESSWELL, K.; ROBERTSON, A.; HUBY, G.; AVERY, A.; SHEIKH, A. The case study approach. BMC Medical Research Methodology, 11:100, p. 1-9, 2011.

http://www.biomedcentral.com/1471-2288/11/100

HODGES, C.; MOORE, S.; LOCKEE, B.; TRUST, T.; BOND, A. The Difference Between Emergency Remote Teaching and Online Learning. EDUCAUSE. https://er.educause.edu/articles/2020/3/the-differencebetween-emergency-remote-teaching-and-onlinelearning

HARRISON, R.; HARRISON, M.. Identity in Online Communities: Social Networking Sites. International Journal of Emerging Technologies \& Society. Vol. 7, No. 2, 2009, pp: $109-124$

KUMARAVADIVELU, B. Toward as postmethod pedagogy. TESOL Quarterly, v. 35, n.4, p. 537-560, 2001.

KUMARAVADIVELU, B. The postmethod condition: (E)merging strategies for second/foreign language teaching. TESOL Quarterly, p. 27-48, 1994.

MAIA, C.; MATTAR, J. ABC da EaD: a educação a distância hoje. Pearson

Prentice Hall, 2008.
UNESCO, 2020. COVID-19: impact on Education. Available on: https://en.unesco.org/covid19/educationresponse.

Access: 24 July 2020.

GACS, A.; SENTA, G.; SHANNON, S. Planned online language education versus crisis-prompted online language teaching: Lessons for the future. Foreign Language Annals. 2020;53:380-392. https://doi.org/10.1111/flan.12460

SANTOS, Elaine Maria; GOMES, Rodrigo Belfort. Emergency remote teaching at EWB-UFx during coronavirus pandemic: Coping with (di)stres. Signo, Santa Cruz do Sul, v. 46, n. 85 , p. 145-156, jan. 2021. ISSN 1982-2014. Disponível em: $<$ https://online.unisc.br/seer/index.php/signo/article/view/ 15696>. doi:https://doi.org/10.17058/signo.v46i85.15696. 